\title{
Are Adolescent Cigarette Smokers Who Use Smokeless Tobacco More Likely to Continue Smoking in the Future than Cigarette-Only Smokers: Results from Waves I and II of the Adolescent Health Survey
}

\author{
Michelle M. O'Hegarty, ${ }^{1}$ Linda L. Pederson, ${ }^{2}$ Katherine J. Asman, ${ }^{2}$ \\ Ann M. Malarcher, ${ }^{1}$ and Sara A. Mirza ${ }^{1}$ \\ ${ }^{1}$ Centers for Disease Control and Prevention, Office on Smoking and Health, 4770 Buford Highway N.E., Mailstop K-50, \\ Atlanta, GA 30341-3717, USA \\ ${ }^{2}$ Research Triangle Institute International, Koger Center, Oxford Building, Suite 119, 2951 Flowers Road South, \\ Atlanta, GA 30341-5533, USA
}

Correspondence should be addressed to Michelle M. O’Hegarty, mohegarty@cdc.gov

Received 15 December 2011; Accepted 4 January 2012

Academic Editors: C. I. Ardern, D. M. Ivanovic, and F. Montanaro

Copyright (C) 2012 Michelle M. O’Hegarty et al. This is an open access article distributed under the Creative Commons Attribution License, which permits unrestricted use, distribution, and reproduction in any medium, provided the original work is properly cited.

\begin{abstract}
We explored whether dual use of smokeless and cigarettes among adolescents predicts continued smoking. Data came from Waves I (1994-95) and II (1996) of the National Longitudinal Study of Adolescent Health, using information from 3,284 Wave I current smokers. Multivariate models were used to assess whether use of smokeless tobacco at Wave I was associated with continuation of cigarette smoking at Wave II, controlling for possible confounders. The prevalence of current cigarette smoking at Wave 1 was 27.9\%; among this group of adolescents and young adults, $14.5 \%$ also used smokeless tobacco. At Wave II, $73.6 \%$ of dual product users and 78.4\% of cigarette-only users in Wave I reported continued smoking ( $\mathrm{OR}=0.71$ [95\% CI 0.52-0.98]). Combined use of cigarette and smokeless tobacco does not appear to be related to continued smoking one year later. Longer-term followups are needed to determine the stability of this relationship for $\geq 1$ year.
\end{abstract}

\section{Introduction}

In the United States, smokeless tobacco use is more common among young white males, American Indians/Alaskan Natives, and people living in southern and Midwestern states than in other groups or parts of the country [1]. Results from the 2009 National Survey on Drug Use and Health indicated that the prevalence for smokeless tobacco use was 3.4\% among persons aged 12 or older. Past month use of smokeless tobacco among young adults (18-25 years of age) was $6.1 \%$ and $2.3 \%$ among youth (12 to 17 years of age) [2]. Past month use of smokeless tobacco among males aged 12 years or older was $6.7 \%$ [2].

Tomar and colleagues [3] recently discussed four arguments that have been used to support the use of smokeless tobacco (ST) for harm reduction: (1) switching from cigarettes to ST would reduce health risks associated with cigarette smoking, (2) ST is effective for smoking cessation, (3) ST is an effective nicotine maintenance product, and (4) ST is not a "gateway" for cigarette smoking. The authors concluded that there is little evidence to support the first three arguments and that most evidence suggests that ST is a gateway for cigarette smoking [3]. In Sweden, after the introduction of snus (which was primarily used by men), smoking prevalence among men and women declined and ST used increased among men suggesting that use of snus may lead to cessation of cigarette smoking [3]. However, this finding has not been replicated in other countries such as Norway, where snus is available. In addition, findings on cessation rates in the USA do not appear to support the conclusion that use of a smokeless product may result in smoking cessation; Zhu et al. found that male smoking 
cessation rates were not higher than female rates $(11.7 \%$ versus $12.4 \%$ ) even though men were more likely to use smokeless tobacco [4].

One issue that was not addressed in the Tomar et al. [3] review was what happens to adolescent smokers who used ST; are they more likely to continue smoking in the future or are they more likely to quit smoking, when compared to adolescents who only smoke cigarettes? If higher levels of addiction result from the use of more than one tobacco product, then the expectation would be that continued smoking might be more likely among those who also used smokeless tobacco. If, on the other hand, ST is used for cessation, then it might be expected that dual product users (cigarettes and ST) would be less likely to continue smoking than single product users. There is some evidence about the progression of use of the products. For example, Severson and Tomar have found that adolescent ST users who had not yet started smoking were more likely to take up smoking than their peers who had not used ST $[5,6]$. Among those who used both ST and cigarettes, many typically started using cigarettes before using smokeless tobacco (Among past month smokeless tobacco users, $85.8 \%$ used cigarettes at some time in their lives, and $38.8 \%$ used cigarettes in the past month) [1]. Determining the relationship of dual use of cigarettes and ST and their continued use may provide important information for programmatic efforts to reduce overall tobacco use among adolescents.

The purpose of the current study was to examine whether current use of ST in addition to current use of cigarettes is related to continuing smoking or to cessation one year later. We used data from the National Longitudinal Study of Adolescent Health (Add Health) Survey to examine this relationship.

\section{Methods}

2.1. Add Health Surveys. Add Health is a school-based longitudinal study of a nationally representative sample of US adolescents who were in grades 7-12 during the 199495 school year (Wave I of data collection). Wave II was conducted in 1996, Wave III in 2001-2002, and Wave IV in 20072008. Because the survey objectives did not remain constant over time, not all questions and data collection components were the same for every Wave. Unfortunately, while a substantial proportion of participants in Wave I were reinterviewed in Wave III approximately 7 years later, the interview did not include some necessary questions on tobacco use and cessation we needed for our study. Therefore, only Wave I and II data from the in-home interviews are included in the present analyses. Complete descriptions of the Add Health sampling, questionnaires, and interview procedures can be found at the University of North Carolina website http://www.cpc.unc.edu/projects/addhealth. This study was approved by CDC's Institutional Review Board.

A brief summary of the data that were used in the current set of analyses is included here. A cluster schoolbased sample was used in Wave I; systematic sampling and stratification were used to ensure representation of high schools (could include grades 7 through 12) that differed with regard to county, urbanicity, size, type, and ethnicity. Students were asked to complete a self-administered inschool questionnaire; approximately 90,000 out of 100,000 who were contacted to participate completed the questionnaire [7]. Parental consent was required for participation in the study. Depending on the requirements of the individual schools, either active or passive consent was used. Topics included social and demographic characteristics, education and occupation of parents, household structure, risk behaviors, self-esteem, health status, friendships, and school year activities. In Wave I, 20,745 out of approximately 90,000 students who completed a self-administered in-school questionnaire were also selected to be interviewed in their homes. Additional topics were included on the in-home survey (i.e., health status, sexual attitudes/behaviors, substance use, and health care utilization, etc.) For Wave II, not all of the students who were in the Wave I in-home survey were eligible for interview; 12th graders from Wave I, those who were disabled and siblings of twins were not retained (169 individuals who reported being in Grade 12 at Wave I were reinterviewed at Wave II and have been retained in the current analyses. Misreporting of grade, repeated a grade, and dropping out and reentering school are possible reasons for their being interviewed in Wave II). Of the approximately 17,000 students (out of the sampled 20,000 who completed the in-home survey) who were in Grades 7-11 and were eligible for Wave II, 15,000 (including both smokers and non smokers) provided Wave II information by in-home interviews, resulting in a response rate of $88.2 \%$. Some respondents in Wave I did not provide information on a grade nor was that information available from the school; these respondents were excluded from this analysis. Hence, the final sample for the present set of analyses included only those in grades 7-11 who reported current smoking at Wave I and were interviewed in Wave II; $N=3284$. The smoking prevalence at Wave I was $27.9 \%$, and among current cigarette smokers at Wave I, 14.5\% were also smokeless tobacco users.

2.2. Variables. Given the exploratory nature of the analyses and the focus on description rather than hypothesis testing, only select variables that have been associated with smoking among adolescents and young adults from Wave I were included in the analyses [8]. Demographic variables (i.e., age, sex, and race/ethnicity) and experience with cigarettes, smokeless tobacco, and alcohol were selected. The number of cigarettes smoked per day was determined from the following question "During the past 30 days, on the days that you smoked, how many cigarettes did you smoke each day?" Three categories of alcohol use were used (binge drinkers were those who drank five or more drinks in a row, at least once in the past year; nonbinge drinkers were those who drank at least once during the past year, but did not drink five or more drinks in a row during the past year, and nondrinkers were those who reported that they did not drink at all during the past year, and that they drank no more than 2-3 times in their life).

Current cigarette smokers were those who smoked on at least 1 of the past 30 days at Wave I at the time of the interview; all others were categorized as not current smokers and 
were not included in the current analyses. Current smokeless tobacco users were those who reported using smokeless during the previous 30 days at Wave I; all others were defined as not current users. The question that determined ST use was "During the past 30 days, on how many days did you use chewing tobacco (such as Redman, Levi Garrett, or Beechnut) or snuff (such as Skoal, Skoal Bandits, or Copenhagen)?" Dual users were those who reported using cigarettes in the past 30 days, as well as ST in the past 30 days. For the present set of analyses, continued smoking was defined as being a current smoker (past 30 days) at both Waves I and II.

Future educational plans, (respondents were asked at Wave I, "on a scale of 1 to 5 , where 1 is low and 5 is high, how likely is it that you will go to college?") depression, and delinquency have been repeatedly demonstrated to be related to tobacco use in both longitudinal and cross-sectional analyses and were also included in the analysis [8-13]. The Feelings scale (Depression scale) was modified from the CES$\mathrm{D}[12,13]$. All 19 questions were coded on a four-point scale, from never or rarely (1) to most or all of the time (4) and refer to feelings the respondent had in the past week. The item scores were summed; scale scores were coded as missing if responses were provided to $80 \%$ or less of the items (14 items or less); no one in these analyses was eliminated because of missing items. If 15 to 18 items were completed, scores were standardized to 19 items. The Delinquency scale consisted of 15 items (i.e., get into a serious physical fight, run away from home, go into a house or building to steal something, etc.) [7]. Using the $80 \%$ rule, if less than 12 items were answered, the scale was counted as missing; if 12-14 items were completed, scores were standardized to 15 items. For the sample we analyzed, 12 individuals were missing a delinquency score.

\subsection{Statistical Analyses. We used SUDAAN 10.0 (RTI Inter-} national, RTP, NC) to take into consideration the complex survey design and adjust for nonresponse. The sampling weight from Wave II was applied to both Waves in the current analyses. Descriptive comparisons were produced using the CROSSTAB procedure, and modeling was carried out using the RLOGIST procedure. Backwards stepwise logistic regression modeling (starting with a full model which contained all variables that were statistically significantly $[P<$ 0.05 by the Wald statistic], related to Wave II smoking status in bivariate models) was conducted to determine characteristics of those Wave I cigarette smokers who were still smoking at Wave II.

\section{Results}

3.1. Prevalence of Cigarette Smoking and Smokeless Tobacco Use at Wave I and Wave II. The smoking prevalence overall at Wave I was $27.9 \%$ and among current cigarette smokers at Wave I, $14.5 \%$ were also smokeless tobacco users. Overall, $7.36 \%$ of the total Wave I sample used smokeless tobacco either in combination with cigarettes or by itself. In unadjusted analysis comparing Wave I current cigarette smokers who also used smokeless tobacco to cigarette smokers who

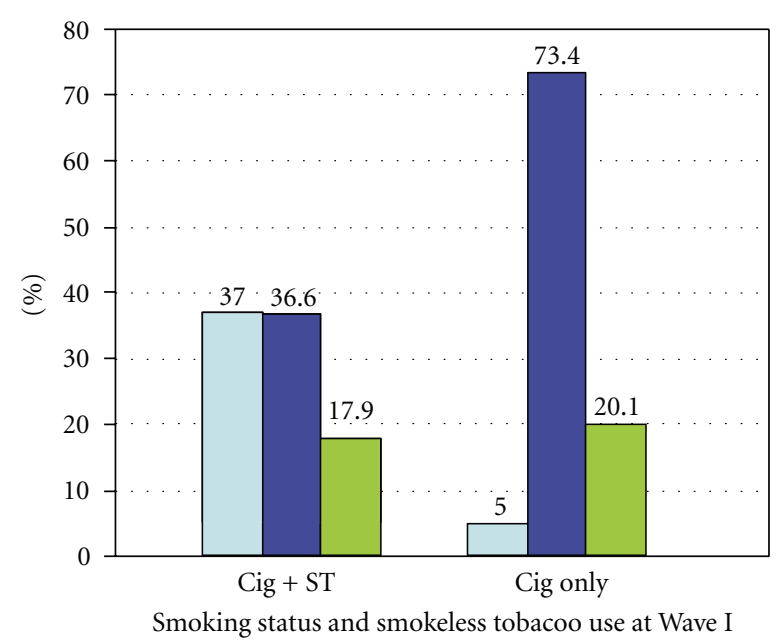

$$
\begin{aligned}
\text { Wave II } & \square \text { Cig + ST } \\
\text { use } & \square \text { Cig only (no ST) } \\
& \square \text { No cig or ST }
\end{aligned}
$$

Figure 1: Cigarette smoking and smokeless tobacco use at Wave II by cigarette smoking and smokeless tobacco use at Wave I: Adolescent Health Study. Wave I current cigarette smoking defined as those who said they smoked on at least 1 of the past 30 days. Current smokeless tobacco use was defined as those who used chewing tobacco during the previous 30 days.

did not use smokeless tobacco (cigarette-only users), we observed differences between these two groups in distributions of gender, race/ethnicity, number of cigarettes smoked per day, binge drinking, and depression. Users of both products were more likely to be male $(81.8 \%)$ than cigarette only users $(44.1 \%)$ as shown in Table 1 . Users of both products were less likely to be non-Hispanic black. Users of both products were also more likely to be binge drinkers $(67.2 \%)$ than cigarette-only users $(55.1 \%)$. Cigarette smokers who also used smokeless tobacco had lower mean depression scores (31.3 versus 32.8) $(P=.077)$ but did not differ from cigaretteonly users in age, number of days smoked in last 30 days, cigarettes per day, future educational plans, or in a measure of delinquency.

When we examined cigarette smoking status at Wave II among both groups from Wave I, we found that the proportion who reported continued cigarette smoking at Wave II was similar (statistically nonsignificant; $P=.1141$ ) between those who used both products $(73.6 \%$ were still smoking at Wave II) and cigarette-only users (78.4\% were still smoking at Wave II) as shown in Figure 1. Among users of both cigarettes and ST at Wave I, 37.0\% continued to use both products at Wave II, while $36.6 \%$ continued using cigarettes only and $17.9 \%$ reported quitting both products. In contrast, for cigarette-only users at Wave I, the majority remained smoking only cigarettes at Wave II (73.4\%), while 5\% of cigarette-only users at Wave I reported using both products at Wave II. Finally, 1.6\% of cigarette-only users at Wave I were ST only at Wave II, and $20.0 \%$ of cigarette-only users at Wave I were not using cigarettes or ST at Wave II. 
TABLE 1: Demographic and other characteristics of current cigarette smokers ${ }^{\mathrm{a}}$ by current smokeless tobacco use ${ }^{\mathrm{b}}$ : Add Health Wave I.

\begin{tabular}{|c|c|c|c|c|c|}
\hline Variable & $\begin{array}{c}\text { No ST use } \\
\text { mean/\% (s.e.) }\end{array}$ & Sample size $(N)$ & $\begin{array}{l}\text { Current ST user } \\
\text { Mean/\% (s.e.) }\end{array}$ & Sample size $(N)$ & $P$ value \\
\hline Age (mean years) & $15.5(0.1)$ & 2847 & $15.7(0.2)$ & 480 & .0961 \\
\hline \multicolumn{6}{|l|}{ Gender } \\
\hline Male & $44.1 \%(1.6)$ & 1249 & $81.8 \%(2.9)$ & 401 & $<.0001$ \\
\hline Female & $55.9 \%(1.6)$ & 1598 & $18.2 \%(2.9)$ & 79 & $<.0001$ \\
\hline \multicolumn{6}{|l|}{ Race/Ethnicity } \\
\hline NH-White & $75.0 \%(2.6)$ & 1834 & $79.5 \%(3.1)$ & 362 & .0862 \\
\hline NH-Black & $8.5 \%(1.4)$ & 287 & $4.4 \%(1.1)$ & 26 & .0002 \\
\hline Hispanic & $10.2 \%(1.5)$ & 436 & $9.6 \%(2.5)$ & 54 & .7682 \\
\hline NH-Other & $6.4 \%(0.9)$ & 281 & $6.6 \%(1.2)$ & 37 & .8848 \\
\hline $\begin{array}{l}\text { Number of days smoked in } \\
\text { past } 30 \text { days (mean) }\end{array}$ & $16.3(0.5)$ & 2847 & $15.8(0.7)$ & 480 & .5518 \\
\hline \multicolumn{6}{|l|}{ Number of Cigarettes/day: } \\
\hline$<1$ cig/day & $4.1 \%(0.4)$ & 112 & $2.8 \%(1.0)$ & 12 & .2274 \\
\hline $1 \mathrm{cig} /$ day & $24.8 \%(1.4)$ & 738 & $18.6 \%(2.3)$ & 100 & .0263 \\
\hline $2-5$ cigs/day & $36.7 \%(1.3)$ & 1076 & $40.0 \%(3.2)$ & 190 & .3119 \\
\hline $6-10$ cigs/day & $13.3 \%(0.9)$ & 403 & $15.2 \%(2.2)$ & 72 & .4226 \\
\hline 11-20cigs/day & $17.5 \%(1.3)$ & 425 & $19.0 \%(2.2)$ & 81 & .5815 \\
\hline$>20$ cigs/day & $3.7 \%(0.5)$ & 87 & $4.4 \%(1.2)$ & 21 & .5041 \\
\hline \multicolumn{6}{|l|}{ Binge drinking ${ }^{\mathrm{c}}$} \\
\hline Binge drinker & $55.1 \%(1.5)$ & 1558 & $67.2 \%(2.9)$ & 326 & $<.0001$ \\
\hline Non-binge drinker & $25.0 \%(1.2)$ & 707 & $11.5 \%(1.7)$ & 61 & $<.0001$ \\
\hline Non-drinker & $20.0 \%(1.1)$ & 564 & $21.3 \%(2.5)$ & 90 & .5836 \\
\hline $\begin{array}{l}\text { Future education Scale } \\
(\text { mean })^{d}\end{array}$ & $3.8(0.1)$ & 2843 & $3.8(0.1)$ & 480 & .3020 \\
\hline Depression scale (mean) ${ }^{\mathrm{e}}$ & $32.8(0.2)$ & 2847 & $31.3(0.5)$ & 480 & .0077 \\
\hline Delinquency scale $(\text { mean })^{\mathrm{f}}$ & $21.9(0.2)$ & 2842 & $23.0(0.5)$ & 474 & .0559 \\
\hline
\end{tabular}

${ }^{a}$ Current smokers were those who said they had smoked on at least 1 of the past 30 days. ${ }^{\text {b Current }}$ ST users were those who used chewing tobacco or snuff on at least 1 of the past 30 days. ${ }^{\mathrm{c}} \mathrm{A}$ binge drinker is one who drank five or more drinks in a row, at least once in the past year. A nonbinge drinker is one who drank at least once during the past year but did not drink five or more drinks in a row during the past year. ${ }^{\mathrm{d}}$ Respondents were asked "On a scale of 1 to 5 ,

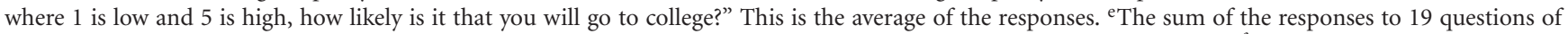

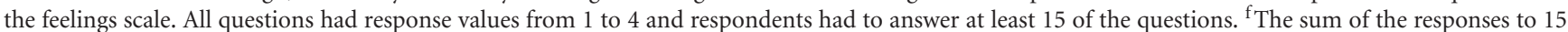
questions of the delinquency scale. All questions had response values from 1 to 4 and respondents had to answer at least 12 of the questions.

3.2. Multivariate Models. Variables that were included in the initial model were (from Wave I) ST use, age, sex, race/ethnicity, number of cigarettes smoked per day, number of days smoked in the past 30 days, binge drinking, feelings scale, depression scale, and future educational plans.

Using multivariate analysis, we assessed whether dual use of cigarettes and smokeless tobacco at Wave I was associated with continuation of cigarette smoking at Wave II, while controlling for demographic characteristics and other variables that were shown to have bivariate relationships with continued smoking (variables included were ST use, race/ethnicity, binge drinking, number of cigarettes smoked per day, number of days smoked, and future educational plans). All variables were included initially in the model. Using stepwise backward regression, we retained the demographic variables in the model and those that were not statistically significant at 0.05 were eliminated (see Table 2 for the final model). Unlike the findings from the unadjusted analysis, smokers who both smoked and used smokeless tobacco at Wave I were less likely to continue smoking at Wave II (OR $=0.71$ [95\% CI $0.52-0.98]$ ) than Wave I cigarette-only users. The final model included gender, race/ethnicity, number of days smoked in the last 30 days, amount smoked per day, alcohol use, and school grade. Depression and delinquency scores were not associated with continued smoking and were not retained in the final model.

\section{Discussion and Summary}

4.1. Summary of Findings and Comparisons with Other Studies. In the current set of analyses, approximately $4 \%$ of the total sample reported dual use of cigarettes and ST $(14.5 \%$ of $27.9 \%=$ approximately $4 \%)$. This figure is very close to the prevalence of $3.8 \%$ found in the most current 2009 National Youth Tobacco Survey (NYTS) for dual use of cigarettes and ST in a similar age group. The applicability of the findings from this set of analyses need to be considered in light of the changes in the environment of tobacco control 
TABLE 2: Odds ratios of continued use and $95 \%$ confidence intervals associated with continued smoking at Wave II ${ }^{\mathrm{a}}$ among current smokers ${ }^{\mathrm{b}}$ at Wave I: Adolescent Health Study.

\begin{tabular}{|c|c|c|c|}
\hline \multirow[b]{2}{*}{ Variable } & \multicolumn{3}{|c|}{ Final model } \\
\hline & Odds Ratio & $95 \% \mathrm{CI}$ & $P$ value \\
\hline \multicolumn{4}{|l|}{ Smokeless tobacco use $\mathrm{e}^{\mathrm{c}}$} \\
\hline No ST use & 1.00 & & .0352 \\
\hline Current ST user & 0.71 & $(0.52-0.98)$ & \\
\hline Age (years) & 1.04 & $(0.95-1.14)$ & .4258 \\
\hline \multicolumn{4}{|l|}{ Gender } \\
\hline Male & 1.00 & $(1.00-1.00)$ & \\
\hline Female & 1.29 & $(1.00-1.67)$ & .0510 \\
\hline \multicolumn{4}{|l|}{ Race/Ethnicity } \\
\hline NH-White & 1.00 & $(1.00-1.00)$ & \\
\hline NH-Black & 0.53 & $(0.36-0.78)$ & .0016 \\
\hline Hispanic & 0.65 & $(0.47-0.89)$ & .0071 \\
\hline NH-Other & 0.99 & $(0.61-1.61)$ & .9783 \\
\hline Number of days smoked in past 30 days & 1.05 & $(1.03-1.06)$ & $<.0001$ \\
\hline \multicolumn{4}{|l|}{ Number of cigarettes/day } \\
\hline$<1$ cig/day & 1.00 & $(1.00-1.00)$ & \\
\hline 1 cig/day & 1.11 & $(0.67-1.85)$ & .6800 \\
\hline $2-5$ cigs/day & 1.73 & $(1.03-2.91)$ & .0393 \\
\hline 6-1 cigs/day & 1.92 & $(0.92-3.98)$ & .0799 \\
\hline $11-20$ cigs/day & 2.22 & $(1.07-4.59)$ & .0325 \\
\hline$>20$ cigs/day & 1.49 & $(0.63-3.54)$ & .4258 \\
\hline \multicolumn{4}{|l|}{ Binge drinking ${ }^{\mathrm{d}}$} \\
\hline Binge drinker & 1.00 & $(1.00-1.00)$ & \\
\hline Non-binge drinker & 0.78 & $(0.56-1.07)$ & .1249 \\
\hline Non-drinker & 0.59 & $(0.43-0.80)$ & .0009 \\
\hline Future education scale ${ }^{\mathrm{e}}$ & 0.90 & $(0.83-0.99)$ & .0233 \\
\hline
\end{tabular}

${ }^{a}$ Continued smoking is one who smoked at Waves I and II. A current smoker at Wave II is one who smoked on at least 1 of the past 30 days. ${ }^{b}$ At Wave I, a current smoker was one who said they had smoked on at least 1 of the past 30 days. ${ }^{\mathrm{C} C u r r e n t}$ ST users were those who used chewing tobacco or snuff on at least one of the past 30 days at Wave I. ${ }^{\mathrm{d}}$ A binge drinker is one who drank five or more drinks in a row, at least once in the past year, at Wave I. A nonbinge drinker is one who drank at least once during the past year, but did not drink five or more drinks in a row during the past year, at Wave I. ${ }^{e}$ Respondents were asked at Wave I, "On a scale of 1 to 5 , where 1 is low and 5 is high, how likely is it that you will go to college?" This is the average of the responses.

in the two time periods. Many efforts aimed at reducing the burden of tobacco use began in the mid 1990s and continue today. The Master Settlement Agreement (MSA) was enacted in 1998. The American Legacy's Truth Campaign was begun under the terms of the MSA and has used state of the art advertising to promote prevention and cessation among youth. In 2009, the Food and Drug Administration was granted the authority to regulate tobacco products. In spite of the sanctions, there is a proliferation of new smokeless tobacco products being developed by the tobacco industry including snus and dissolvables. Therefore, it is important to examine dual product use and the implications for future tobacco use behavior. Examination of whether dual users are less likely to quit tobacco use completely needs to be addressed in light of the current environment. Are dual users more or less likely to quit tobacco use and are they more or less likely to relapse than single product users?
The use of both ST and cigarettes found in the current analysis is lower than that found in analyses of earlier years of the NYTS. However, the NYTS analyses were not limited to dual use of smokeless tobacco but included all other types of tobacco products [14]. Bombard and colleagues using data from the 2002 and 2004 National Youth Tobacco Surveys (NYTS) found that among current cigarette smokers, $62 \%$ of male adolescents (in grades 6-12) and 31\% of female adolescents also used at least one other tobacco product in the past 30 days (poly tobacco users) including most commonly cigars and/or ST [14], which may account at least in part for the differences between the current results and the earlier ones. Poly tobacco use does not occur only among adolescents but continues into adulthood. In secondary analyses of information from ten states that included relevant questions in the Behavior Risk Factor Surveillance System (BRFS), Bombard and colleagues also found that over $20 \%$ 
of young adult males who were current smokers were also current users of additional tobacco products [15]. Dual use of products may promote continuation of nicotine dependence [16] and may contribute to high levels of tobaccorelated disease and death in the US [17].

Few studies have examined the influence of multiple tobacco product use on future tobacco use behavior among adolescents. The results from the unadjusted analyses in this study suggest that adolescent cigarette smokers who also use smokeless tobacco may not be at greater risk of continued tobacco use than cigarette-only smokers over a one-year followup period. Given that the follow-up time period was relatively short and that adolescence is a period of experimentation, it is important that the relationships between types of tobacco use and continued smoking be assessed over longer periods. Future studies should attempt to incorporate questions on new and emerging tobacco products such as new snuff, snus products, orbs, and other dissolvable tobacco products.

4.2. Limitations. The findings in this study are subject to a few limitations. First, the data used in this analysis are between fifteen and seventeen years old. However, we selected the Add Health data set because it is a longitudinal study, and we were able to assess students' tobacco and alcohol use as well as psychological aspects at two different time periods. We were not able to locate any more current data sets that provide the same longitudinal information. As noted above, the prevalence of dual use in this study is very similar to that reported in the 2009 NYTS.

Second, we were not able to address why cigarette smokers were using smokeless tobacco (i.e., for cessation, for use when they could not smoke, products were available), so we could not include reasons for use in the analyses. These questions could be addressed in future qualitative studies. Third, several measures to assess binge drinking have been used in the published literature [18]. We selected one that of using five or more drinks in a row at least once in the past year to define binge drinkers. Other measures for binge drinking such as five or more drinks in a row during the prior two week interval might have shown different results. Third, the use of passive consent might compromise the representativeness of the sample, depending on the extent of refusals.

4.3. Implications of the Findings and Recommendations. Understanding adolescent use of smokeless tobacco, cigarettes, and both products provides information that may be useful in tobacco cessation and prevention programs for adolescents. The 2008 Update to the Public Health Services guidelines for Treating Tobacco Use and Dependence concluded that clinicians should ask their pediatric and adolescent patients about tobacco use and provide strong messages that stress the importance of abstaining from tobacco use [19]. Given that new tobacco products are constantly being made available, it seems that it would be important for clinicians to ask about specific categories of products individually [19]. Because dentists and dental clinicians are frequently the first people to see adverse effects of smokeless use, the same suggestion about asking about use as described above can be made for these practitioners. Strategies that may be effective with youth include increasing the cost of tobacco products, including health warning labels on all noncigarette tobacco products and directing mass media and ad campaigns to users of all tobacco products [14]. Self-help programs delivered by internet, mail, or phone may also be effective means at reducing the burden of tobacco dependent.

\section{Disclosure}

Michelle O'Hegarty has no financial disclosures. Linda Pederson has no financial disclosures. Katherine Asman has no financial disclosures. Ann Malarcher has no financial disclosures. Sara Mirza has no financial disclosures.

\section{Disclaimer}

The finds and conclusions in this paper are those of the authors and do not necessarily represent the official position of the US Centers for Disease Control and Prevention.

\section{Acknowledgments}

This paper uses data from Add Health, a program project directed by Kathleen Mullan Harris and designed by J. Richard Udry, Peter S. Bearman, and Kathleen Mullan Harris at the University of North Carolina at Chapel Hill, and funded by GRANT P01-HD31921 from the Eunice Kennedy Shriver National Institute of Child Health and Human Development, with cooperative funding from 23 other federal agencies and foundations. Special acknowledgment is due to Ronald R. Rindfuss and Barbara Entwisle for assistance in the original design. Information on how to obtain the Add Health data files is available on the Add Health website (http://www.cpc.unc.edu/addhealth). No direct support was received from GRANT P01-HD31921 for this analysis. The authors also wish to acknowledge the assistance of Herbert H. Severson, Oregon Research Institute for his review and comments, India A. Hayes, Northrop Grumman, for her graphic assistance, Jennifer Bombard, Centers for Disease Control and Prevention, and Joyce Tabor, University of North Carolina at Chapel Hill for their editing assistance with this paper.

\section{References}

[1] Substance Abuse and Mental Health Services Administration, Office of Applied Studies, The NSDUH Report: Smokeless Tobacco Use, Initiation, and Relationship to Cigarette Smoking:2002 to 2007, Rockville, Md, USA, February 2009, http:// www.oas.samhsa.gov/2k9/smokelessTobacco/smokelessTobacco.pdf.

[2] Substance Abuse and Mental Health Services Administration, Results from the 2009 National Survey on Drug Use and Health: National Findings, Office of Applied Studies, NSDUH Series H-38A, HHS Publication No. SMA 10-4586 Findings, Rockville, Md, USA, September 2010, http://www.oas.samhsa.gov/ NSDUH/2k9NSDUH/2k9ResultsP.pdf. 
[3] S. L. Tomar, B. J. Fox, and H. H. Severson, "Is smokeless tobacco use an appropriate public health strategy for reducing societal harm from cigarette smoking?" International Journal of Environmental Research and Public Health, vol. 6, no. 1, pp. 10-24, 2009.

[4] S. H. Zhu, J. B. Wang, A. Hartman et al., "Quitting cigarettes completely or switching to smokeless tobacco: do US data replicate the swedish results?" Tobacco Control, vol. 18, no. 2, pp. 82-87, 2009.

[5] H. H. Severson, K. K. Forrester, and A. Biglan, "Use of smokeless tobacco is a risk factor for cigarette smoking," Nicotine and Tobacco Research, vol. 9, no. 12, pp. 1331-1337, 2007.

[6] S. L. Tomar, "Is use of smokeless tobacco a risk factor for cigarette smoking? The U.S. experience," Nicotine and Tobacco Research, vol. 5, no. 4, pp. 561-569, 2003.

[7] Add Health, "Social, behavioral, and biological linkages across the life course," http://www.cpc.unc.edu/projects/addhealth.

[8] S. L. Tyas and L. L. Pederson, "Psychosocial factors related to adolescent smoking: a critical review of the literature," Tobacco Control, vol. 7, no. 4, pp. 409-420, 1998.

[9] J. J. Koval, L. L. Pederson, C. A. Mills, G. A. McGrady, and S. C. Carvajal, "Models of the relationship of stress, depression, and other psychosocial factors to smoking behavior: a comparison of a cohort of students in Grades 6 and 8," Preventive Medicine, vol. 30, no. 6, pp. 463-477, 2000.

[10] L. L. Pederson, J. J. Koval, S. S. H. Chan, and X. Zhang, "Variables related to tobacco use among young adults: are there differences between males and females?" Addictive Behaviors, vol. 32, no. 2, pp. 398-403, 2007.

[11] D. W. Brook, C. Zhang, G. Rosenberg, and J. S. Brook, "Maternal cigarette smoking during pregnancy and child aggressive behavior," American Journal on Addictions, vol. 15, no. 6, pp. 450-456, 2006.

[12] L. S. Radloff, "The CES-D Scale: a self-report depression scale for research in the general population," Applied Psychological Measurement, vol. 1, no. 3, pp. 385-401, 1977.

[13] L. S. Radloff, "The use of the Center for Epidemiologic Studies Depression Scale in adolescents and young adults," Journal of Youth and Adolescence, vol. 20, no. 2, pp. 149-166, 1991.

[14] J. M. Bombard, V. J. Rock, L. L. Pederson, and K. J. Asman, "Monitoring polytobacco use among adolescents: do cigarette smokers use other forms of tobacco?" Nicotine and Tobacco Research, vol. 10, no. 11, pp. 1581-1589, 2008.

[15] J. M. Bombard, L. L. Pederson, D. E. Nelson, and A. M. Malarcher, "Are smokers only using cigarettes? Exploring current polytobacco use among an adult population," Addictive Behaviors, vol. 32, no. 10, pp. 2411-2419, 2007.

[16] A. K. McClave-Regan and J. Berkowitz, "Smokers who are also using smokeless tobacco products in the US: a national assessment of characteristics, behaviours and beliefs of 'dual users," Tobacco Control, vol. 20, no. 3, pp. 239-242, 2011.

[17] CDC Statement for Hearing Entitled, Smokeless Tobacco: Impact on the Health of Our Nation's Youth and Use in Major League Baseball, House Energy and Commerce Subcommittee on Health, 2010.

[18] H. Wechsler and S. B. Austin, "College alcohol study, binge drinking: the five/four measure," Journal of Studies on Alcohol, vol. 59, no. 1, pp. 122-124, 1998, http://hsph.harvard.edu/cas/ Documents/54/.

[19] M. C. Fiore, C. R. Jaen, T. B. Baker et al., Treating Tobacco Use and Dependence, Clinical Practice Guideline, 2008 Update, Public Health Service, Rockville, Md, USA, 2008. 


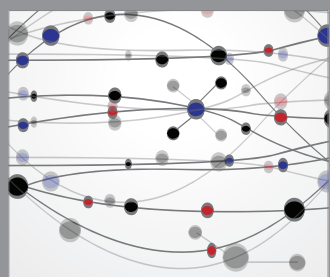

The Scientific World Journal
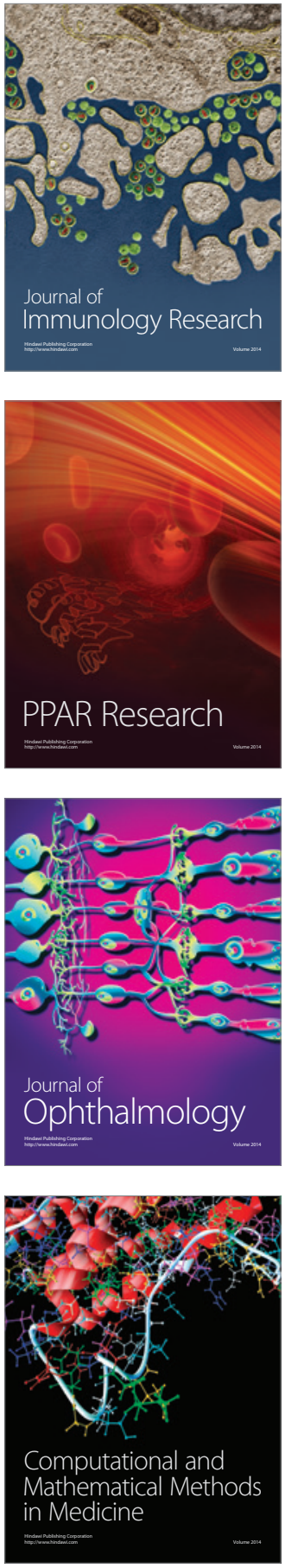

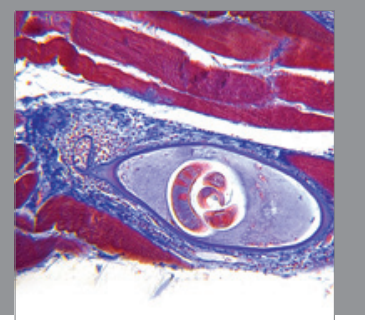

Gastroenterology

Research and Practice
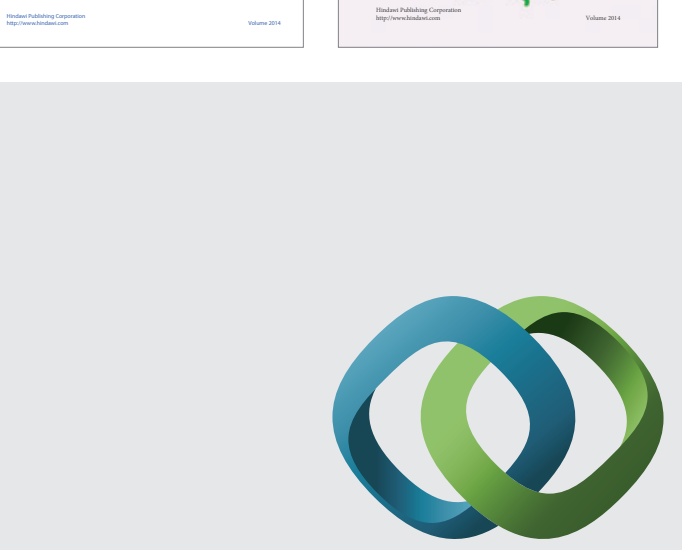

\section{Hindawi}

Submit your manuscripts at

http://www.hindawi.com
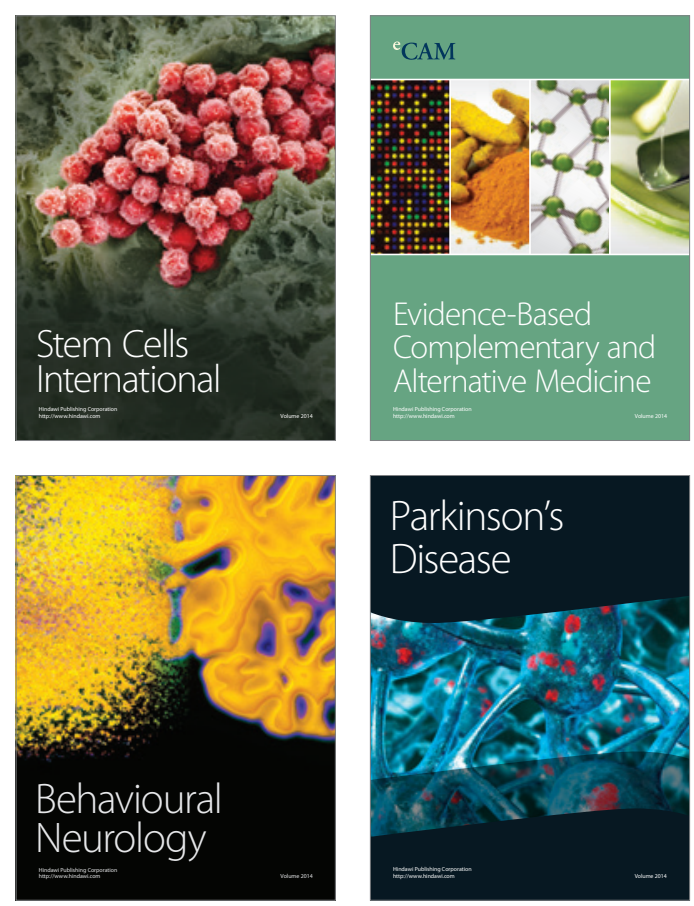

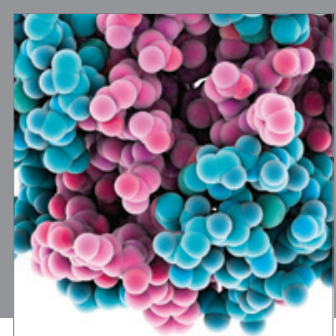

Journal of
Diabetes Research

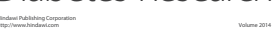

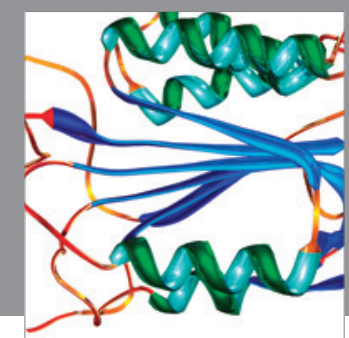

Disease Markers
